\title{
Opposite Responses of Mesolimbic Dopamine System to Controllable and Uncontrollable Aversive Experiences
}

\author{
Simona Cabib' and Stefano Puglisi-Allegra ${ }^{2}$ \\ 1'Istituto di Psicobiologia e Psicofarmacologia, CNR Roma 1-00198, Italy and 2Dipartimento di Psicologia, \\ Universitá di Roma "La Sapienza," Roma 1-00185, Italy
}

\begin{abstract}
It has been previously shown that rodents exposed to stressful experiences show a biphasic response of the mesolimbic dopamine (DA) system, that is, initial increase of DA release followed by a decrease below control levels (Puglisi-Allegra et al., 1991). Evidence is now presented showing that mice exposed to a series of foot shocks show an increase of DA release in the nucleus accumbens septi (NAS) if they are allowed to control the shock experience (shocked condition) and a decrease of DA release in this brain area if they are not allowed to exert any control (yoked condition). These results indicate that escapable/controllable and inescapable/uncontrollable aversive experiences elicit opposite responses from the mesolimbic DA system. Mice exposed to the apparatus without receiving shock (sham condition) show a time-dependent biphasic evolution mesolimbic DA release in line with previous reports indicating that confinement in an unknown environment represents a stressful experience for mice. Moreover, exposure to the sham condition for a time comparable to the duration of shock and yoked exposure induces a mesolimbic DA response only quantitatively different from the response of the yoked group but qualitatively different from the response of the shocked mice. These results suggest that in environmental conditions that allow behavioral control, enhanced mesolimbic DA release is maintained regardless of the intensity of the aversive stimuli. On the other hand, evaluation of changes in acid DA metabolites levels in the frontal cortex (FC) of mice exposed to the shocked, yoked, and sham conditions suggests that stressful experiences characterized by a different intensity of the aversive stimuli could elicit graded responses in the FC DA system. Taken together, the present results may indicate that the initial activation of the mesolimbic DA system induced by stressful experiences accompanies the organism's attempts to cope behaviorally with such a pressure while the subsequent inhibition takes over when, despite the efforts made by the organism, no behavioral coping is possible.
\end{abstract}

[Key words: nucleus accumbens septi, frontal cortex, behavioral coping, aversion, shock, controllability, dopamine, stress]

\footnotetext{
Received July 26, 1993; revised Oct. 21, 1993; accepted Nov. 24, 1993.

Correspondence should be addressed to $\mathrm{S}$. Cabib, Istituto di Psicobiologia e Psicofarmacologia, via Reno I Roma I-00198, Italy.

Copyright (c) 1994 Society for Neuroscience $0270-6474 / 94 / 143333-08 \$ 05.00 / 0$
}

Considerable evidence from preclinical and clinical investigation implies disturbances of mesolimbic and mesocortical dopamine (DA) function in the pathophysiology of several psychiatric disorders (Willner, 1983; Swerdlow and Koob, 1987; Zacharko and Anisman, 1991). On the other hand, stress is considered to play a basic role in the etiology of various psychopathologies either as primary cause or precipitating factor (Stevens, 1979; Willner, 1983; Zacharko and Anisman, 1991). Consequently, the effects of stressful experiences on brain DA responses have been the object of considerable preclinical research (Blanc et al., 1980; Herman et al., 1982; Dunn and File, 1983; Deutch et al., 1985; Cabib et al., 1988; Abercrombie et al., 1989; Imperato et al., 1991; Puglisi-Allegra et al., 1991).

Recently it has been shown that exposure to acute stress produces a time-dependent biphasic alteration of DA release in the nucleus accumbens septi (NAS): an initial increase of DA release is followed by a decrease below control levels (Puglisi-Allegra et al., 1991). This effect was evident in two species, rat and mouse, and under different stressful conditions (Puglisi-Allegra et al., 1991). Moreover, reduced DA release during prolonged stress was not due to exhaustion of DA synthesis or depletion of DA pools since restrained rats were able to respond with a new increase of DA outflow when released from the restraining apparatus (Imperato et al., 1991; Puglisi-Allegra et al., 1991).

The two responses elicited by exposure to aversive conditions were modulated in different ways by previous stress experiences. The initial increase of DA release was reduced by repeated exposure to the stressor (Imperato et al., 1992) while the subsequent inhibition of DA release was anticipated (Imperato et al., 1993). Moreover, exposure to repeated stress during postnatal development eliminated the increase of DA release elicited by short stressful experiences in adult life without affecting the inhibition of DA release induced by prolonged stress (Cabib et al., 1993).

Taken together, these results suggest that the increase and the decrease of DA release observed during exposure to aversive situations in the NAS are different responses possibly dependent on interaction with different neural systems (Puglisi-Allegra et al., 1991). These different responses could be explained in terms of the meaning that aversive conditions have for the organism (Puglisi-Allegra et al., 1991; Imperato et al., 1993). As the organism faces aversive and potentially dangerous events it will first attempt to cope behaviorally with such a pressure. The NAS is a brain struclure considered to be involved in activation that increases probability and vigor of responses as well as in motor processes (Simon and Le Moal, 1984; Le Moal and Simon, 1991); therefore, activation of the mesoaccumbens DA system 
may characterize the initial reaction to an aversive condition. But when, despite the efforts made by the organism, no behavioral coping is possible, a different emotional response takes place that leads to inhibition of DA functioning and possibly to behavioral impairment (Puglisi-Allegra et al., 1991; Imperato et al., 1993).

This leads to the hypothesis that in environmental conditions that allow behavioral coping inhibition of mesolimbic DA release should not be produced.

A large body of research has pointed to the different behavioral and physiological effects produced by escapable-controllable and inescapable-uncontrollable aversive situations, many of which are of great relevance owing to their clinical implications (Weiss et al., 1981; Laudenslager et al., 1983; MacLennan and Maier, 1983; Ievine and Wiener, 1989; Zacharko and Anisman, 1991). The basic technique used by these studies is the shocked-yoked situation in which pairs of animals are subjected to a series of electric shock with only one animal being able to interrupt shock delivery for both by means of various behavioral responses. In this way the two subjects receive the same amount of shock but experience it either in a coping or in a noncoping situation. Consequently, this appears to be the choice experimental condition for testing the above-mentioned hypothesis.

The following experiments were designed to investigate the effects of the shocked-yoked situation on DA and DA metabolites in the NAS and frontal cortex (FC) of mice. The use of the species Mus musculus offers great advantages for this kind of study. Most of the more recent results on the effects of controllablc versus uncontrollablc aversive experiences have been obtained in mice (Prince and Anisman, 1990; Zacharko and Anisman, 1991) and a number of strain-dependent differences in the effects of unavoidable stress have been shown in this species (Cabib et al., 1985, 1988, 1990, 1991; Zacharko et al., 1987; Shanks and Anisman, 1988; Shanks et al., 1990, 1991). These studies have been conducted in inbred strains of mice from which recombinant inbred (RI) strains are available that have been recently proposed as a choice experimental method in behavioral genetic studies aimed at understanding individual susceptibility to behavioral pathology (Plomin, 1990; GoraMaslak et al., 1991; Oliverio et al., 1992).

\section{Materials and Methods}

Subjects. Male DBA/2 mice (Charles River Co. Italy) weighing 20-23 $\mathrm{gm}$ were used for these experiments. The choice of the DBA $/ 2$ strain was due to the results previously obtained in these mice (Cabib et al., 1989; Puglisi-Allegra et al., 1991). Upon their arrival, the animals were housed five to a standard laboratory cage $(27 \times 21 \times 13.5 \mathrm{~cm})$ with food and water at libitum, and maintained in a $12 \mathrm{hr} / 12 \mathrm{hr}$ light/dark cycle (light on between 7 A.M. and 7 P.M.). Experiments were always performed during the second half of the light cycle. All mice were handled and accustomed to the environment where they were to be killed (a room separate from the colony room). Seven groups of mice $(n=7-$ 9) were used for the experiments.

Procedure. The experimental procedure was adapted from Anisman et al. (1978). The apparatus consisted of two pairs of identical opaque Plexiglas shuttle boxes, $29.5 \times 14.5 \times 20 \mathrm{~cm}$, with a stainless steel grid floor through which shock was delivered. Each box was divided into two compartments $(14.5 \times 14.5 \mathrm{~cm})$ by an opaque Plexiglas wall with an opening that could be closed by a sliding door. The boxes were placed inside a sound attenuated cubicle and illuminated by a $60 \mathrm{~W}$ light.

Mice of one group (shocked) were placed individually in the shuttle boxes and received the escape trials. On each trial, shock $(50 \mathrm{~Hz}$. scrambled shock of $150 \mu \mathrm{A}$ ) was presented for $4 \mathrm{sec}$, after which the door separating the two compartments opened, thus permitting escape. Shock delivery was interrupted by escape. In the case of failure to escape shock was interrupted after $24 \mathrm{sec}$, and the interval between each trial was 9 sec. Mice of the second group (yoked) were placed individually in the paired shuttle boxes and exposed to the shocks over which behavioral control was not possible. For these animals, shock onset occurred at exactly the same time as it did for mice of the shocked group. However, shock offset occurred when their paired partners successfully escaped from the shock. Thus, both escapably and inescapably shocked mice received an identical amount of shock at exactly the same time, but only mice in the escapable condition could terminate shock by making the appropriate response.

Mice in the third group served as the nonshocked condition (sham). These animals were placed individually in the shuttle boxes for a period that matched the other two groups $(60 \mathrm{~min})$ but shock was not delivered. Mice coming from a fourth group (control) were killed immediately upon removal from their home cage. Finally, since different results indicate that exposure to a novel environment elicits stress-like responses in mice (Cabib et al., 1990; Prince and Anisman, 1990), two other groups were exposed to the apparatus without shock delivery for 10 and $120 \mathrm{~min}$ before death to investigate possible time-dependent changes of DA metabolism in the NAS. Mice from a seventh group served as controls $(0 \mathrm{~min})$ and were killed as previously described for the control group.

Neurochemical analysis. All subjects were killed by decapitation followed by immediate head freezing. This method was preferred to microwave focusing since the latter procedure requires the animals to be restrained, a condition that produces stress responses (Dunn and File, 1983; Puglisi-Allegra et al., 1991). Consequently, altered brain DA metabolism in control mice could not be ruled out, which may introduce an uncontrollable experimental variable. Moreover, immediate head freezing allows concentrations of 3-methoxytyramine (3-MT) comparable or lower to those obtained by microwave irradiation (Vulto et al., 1986; Green et al., 1988; Wood et al., 1988; Puglisi-Allegra and Cabib, 1990 ) to be obtained and both increasc and decrcase of the metabolite following treatments known to produce these effects to be evaluated (Puglisi-Allegra and Cabib, 1990; Cabib and Puglisi-Allegra, 1991; Puglisi-Allegra et al., 1991). Finally, it has been reported that in the NAS, acute restraint induces time-dependent variations of 3-MT concentrations in mice killed by this method, similar to the variations observed for extracellular DA detected through intracerebral microdialysis in restrained rats (Puglisi-Allegra et al., 1991).

After decapitation the head was plunged directly into liquid nitrogen contained in a thermic box and left for $10 \mathrm{sec}$. The frozen head was stored at $-10^{\circ} \mathrm{C}$ to allow it to reach a more manageable temperature before brain removal. The brain was then fixed vertically on the freeze plate of a freezing microtome. The freeze plate was used as a refrigerating table for punching, the temperature being maintained at $-10^{\circ} \mathrm{C}$. Punches were obtained from brain slices (frontal scctions) no thicker than 300 $\mu \mathrm{m}$. The coordinates were measured according to the atlas of Sidman et al. (1970) (coronal sections), as follows: $\mathrm{FC}=$ two slices from section 95 to 140 ( $2.3 \mathrm{~mm}$ stainless steel tube); NAS = four slices from section 141 to 210 . Stainless steel tubes of $1.1 \mathrm{~mm}$ inside diameter were used to punch NAS. The tissue samples were stored in liquid nitrogen until the day of the analysis.

DA, 3,4-dihydroxyphenylacetic acid (DOPAC), homovanillic acid (HVA), and 3-MT were determined simultaneously utilizing a reversephase high-performance liquid chromatography (HPLC) procedure coupled with electrochemical detection (Cabib et al., 1988, 1989; PuglisiAllegra and Cabib, 1990; Cabib and Puglisi-Allegra, 1991; Puglisi-Allegra et al., 1991). 3-MT levels were reported only for NAS since this metabolite was undetectable with our analytical method in FC. On the day of the analysis frozen samples were weighed and homogenized in $0.1 \mathrm{~N} \mathrm{HClO}_{4}$ containing $6 \mathrm{~mm} \mathrm{Na}$-metabisulfite and $1 \mathrm{~mm}$ EDTA. The homogenates were centrifuged at $10,000 \times g$ for $20 \mathrm{~min}$ at $4^{\circ} \mathrm{C}$. Aliquots of the supernatant were transferred to the HPLC system. The HPLC system consisted of a Waters 460 electrochemical (EC) detector with a glass-carbon working electrode and a pump (Waters 510 ). The potential was set at $800 \mathrm{mV}$ (vs $\mathrm{Ag}-\mathrm{AgCl}$ reference electrode). The column, a Bondapak phenyl column (10 $\mu \mathrm{m}$ particle size, $300 \times 3.1 \mathrm{~mm}$ i.d. $)$, was purchased from Waters Assoc. The flow rate was $1.1 \mathrm{ml} / \mathrm{min}$. The mobile phase consisted of $4 \%$ methanol in $0.1 \mathrm{M} \mathrm{Na-phosphate} \mathrm{buffer,}$ pH 2.9,0.1 mm Na, EDTA, and 1 -octane sulfonic acid Na salt (Aldrich) $0.5 \mathrm{~mm}$; 3,4-dihydroxyhydrocinnamic acid (Aldrich) was used as the internal standard.

Statistics. Results are reported in figures as percentage (\%) changes from control values (mean \pm SEM). Control valucs arc rcported in figure legends. Statistical analyses were performed on levels (ng/gm wet 

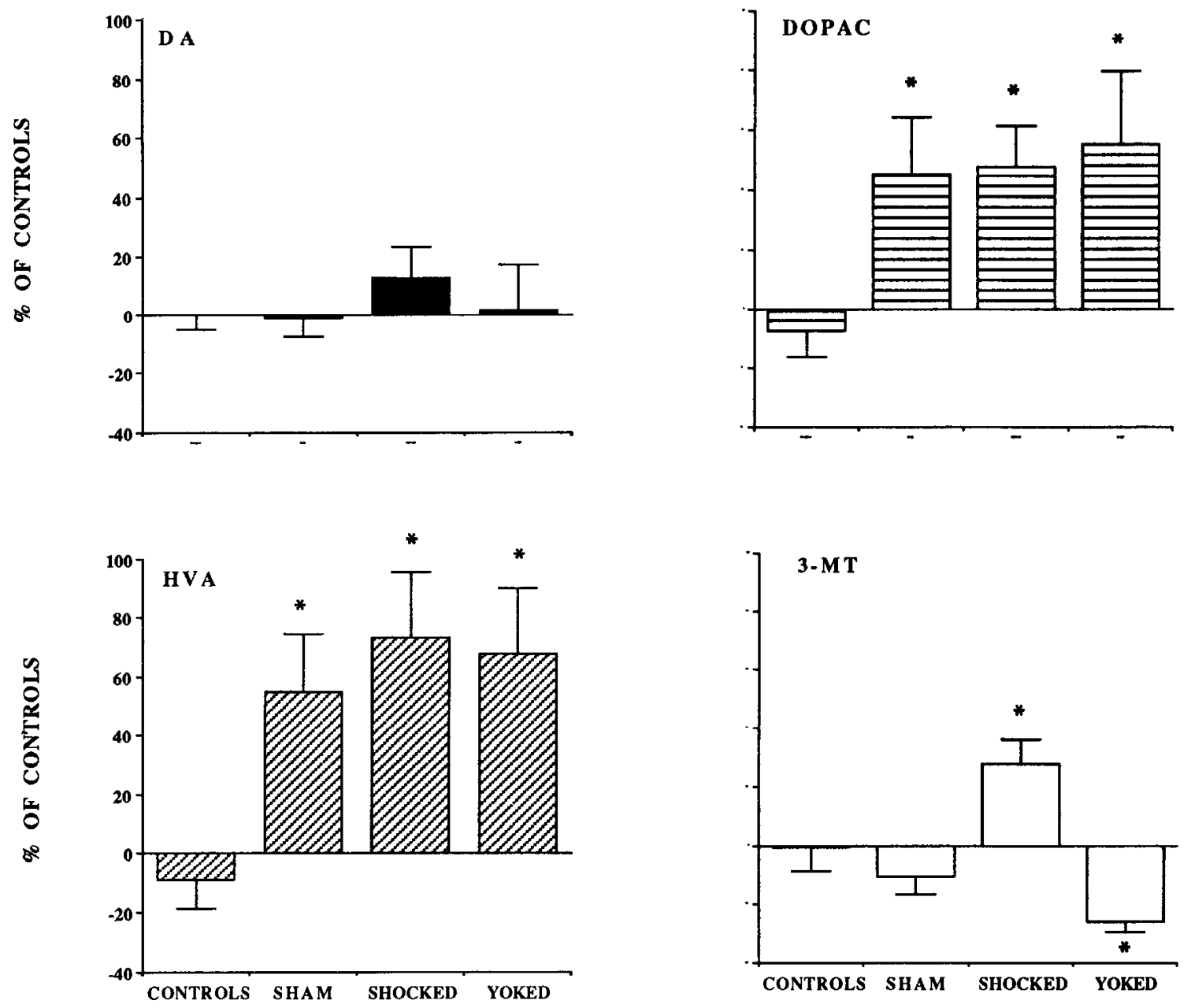

Figure 1. Effects of 60 min exposure to the apparatus (SHAM), the controllable shocks (SHOCKED), the uncontrollable shocks (YOKED), and no treatment (CONTROLS) on DA and DA metabolites in the NAS of DBA/2 mice. Results are expressed as percentage changes ( \pm SEM) from CONTROLS levels. Statistical analyses were performed on tissue levels (ng/gm wet weight). Levels in controls were as follows: DA $=12,769 \pm$ $388 ; \mathrm{DOPAC}=1133 \pm 67 ; \mathrm{HVA}=1082 \pm 83 ; 3-\mathrm{MT}=68.7 \pm 5.1 .{ }^{*}, p<0.05$ in comparison with controls (Duncan test).

weight) of DA and metabolites by one-way ANOVA (factors being either treatment $=4$ levels: shocked, yoked, sham, control; or duration of exposure to the apparatus $=3$ levels: $0,10,120 \mathrm{~min}$ ). Individual between-groups comparisons were performed by post hoc test (Duncan).

\section{Results}

In Figure 1 are shown data obtained in the NAS of control, sham, shocked, and yoked groups. For DA, one-way ANOVA did not reveal any significant effect of the different treatments $[F(3,37)=0.501 ; \mathrm{NS}]$. For DOPAC, ANOVA revealed a significant effect of the different treatments $[F(3,37)=3.15 ; p<$ 0.05]. Post hoc analysis revealed significant effects of each of the three treatments in comparison with control. No difference among the three treated groups was evident. For HVA, ANOVA revealed significant effects of the different treatments $[F(3,37)$ $=4.012 ; p<0.02]$. Post hoc analysis revealed significant effects of each of the three treatments in comparison with control. No difference among the three treated groups was evident. For 3-MT, ANOVA revealed a significant effect of the different treatments $[F(3,37)=9.033 ; p<0.001]$. Post hoc analysis revealed significant effects of shocked and yoked conditions in comparison with control. No difference was revealed between sham and control groups or between sham and yoked groups and a significant difference was found between shocked and all the other groups.

These results indicate that the three treatments significantly increase DOPAC and HVA levels in the NAS. On the other hand, exposure to the apparatus did not significantly affect 3-MT levels and shock and yoked conditions had opposite effects (increase and decrease, respectively) on the levels of this DA metabolite.

In Figure 2 are shown data obtained in the FC of control, sham, shocked, and yoked groups. For DA, one-way ANOVA did not reveal any significant effect of the different treatments $[F(3,37)=0.71$; NS $]$. For DOPAC, ANOVA revealed significant effects of the different treatments $[F(3,37)=10.61 ; p<0.001]$. Post hoc analyses revealed significant effects of shocked condition in comparison with control group. No difference was revealed between sham and control groups and a significant difference was found between yoked and all other groups. For HVA, one-way ANOVA did not reveal any significant effect of the different treatments $[F(3,37)=2.25$; NS $]$.

These results indicate that shocked and yoked conditions but not exposure to the apparatus significantly increase DOPAC 

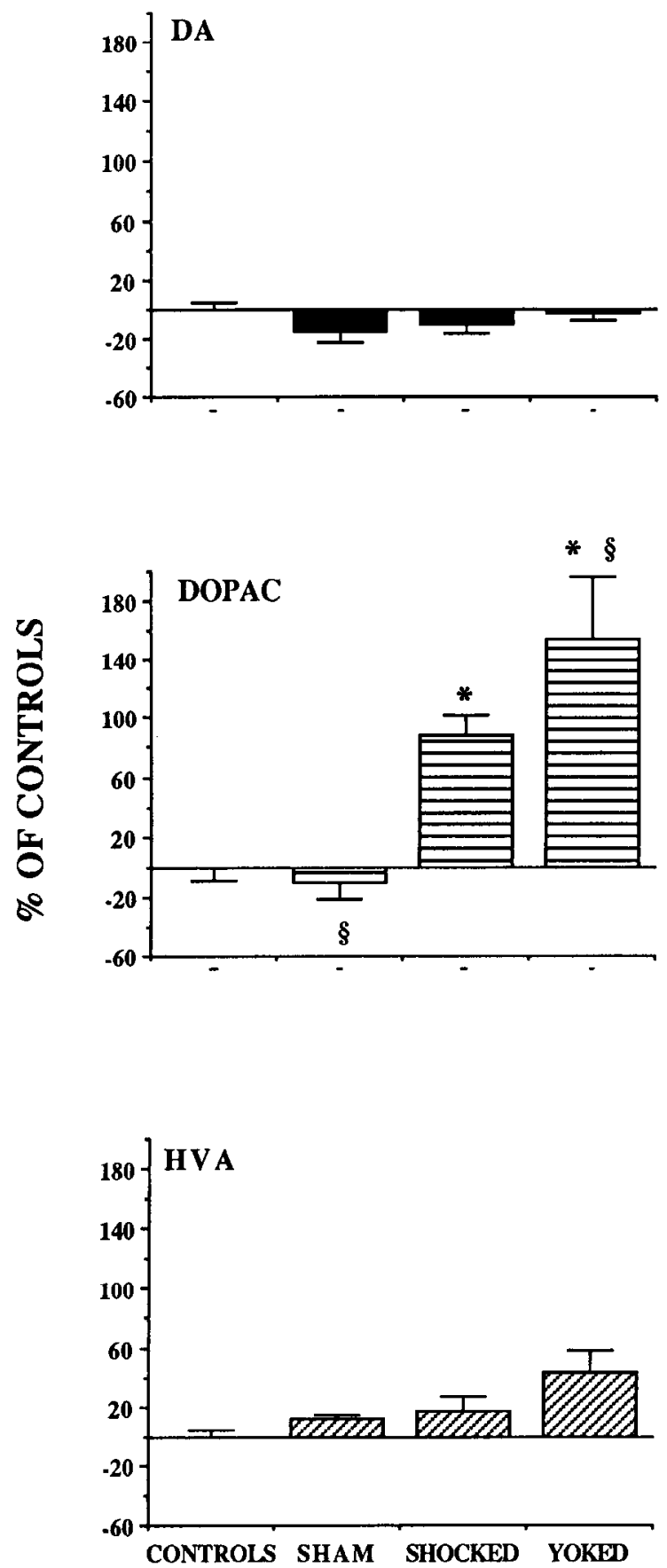

Figure 2. Effects of 60 min exposure to the apparatus (SHAM), the controllable shocks (SHOCKED), the uncontrollable shocks (YOKED), and no treatment (CONTROLS) on DA and DA metabolites in the FC of DBA/ 2 mice. Results are expressed as percentage changes $( \pm \mathrm{SEM})$ from CONTROLS levels. Statistical analyses were performed on tissue levels ( $\mathrm{ng} / \mathrm{gm}$ wet weight). Levels in controls were as follows: DA $=189$ $\pm 19 ;$ DOPAC $=35 \pm 6 ; \mathrm{HVA}=114 \pm 6.4 .^{*}, p<0.05$ in comparison with controls (Duncan test); $\dagger, p<0.05$ in comparison with shocked group (Duncan test).

levels in the FC of the mice used for these experiments. Moreover, a graded response of cortical DOPAC levels was evident in mice exposed to the shocked and yoked conditions.

In Figure 3 are shown data obtained in the NAS of control mice (labeled " 0 ") and mice exposed to the apparatus for 10 and $120 \mathrm{~min}$ without receiving shock. For DA, one-way ANO-
VA did not reveal any significant effect of the different treatments $[F(2,29)=0.46 ;$ NS $]$. For DOPAC, ANOVA revealed a significant effect of the different treatments $[F(2,29)=28.67 ; p$ $<0.0001]$. Post hoc analysis revealed significant effects of 10 and $120 \mathrm{~min}$ exposure to the apparatus in comparison with controls $(0)$. No difference among the two treated groups was evident. For HVA, ANOVA revealed a significant effect of the different treatments $[F(2,29)=12 ; p<0.0005]$. Post hoc analysis revealed significant effects of both 10 and $120 \mathrm{~min}$ of exposure to the apparatus in comparison with controls. No difference among the two treated groups was evident. For 3-MT, ANOVA revealed a significant effect of the different treatments $[F(2,29)=30.81 ; p<0.0001]$. Post hoc analysis revealed significant effects of 10 and 120 min exposure to the apparatus in comparison with controls. A significant difference was also found between the two treated groups.

A significant increase in DOPAC and HVA levels was produced by either 10 or 120 min exposure to the shock apparatus in the NAS of the mice used for these experiments. On the other hand, exposure to the apparatus for 10 and $120 \mathrm{~min}$ had opposite effects (increase and decrease, respectively) on 3-MT levels in this brain area.

\section{Discussion}

The present results show that mice exposed to the same amount of shock for the same length of time present an increase of 3-MT levels in the NAS if they are allowed to control the situation and a decrease in 3-MT levels in the same area if they are prevented from exerting any control. On the other hand, in both conditions, shocked mice show an increase in DOPAC and HVA levels and no change in DA levels.

A number of studies have pointed to 3-MT in brain tissue as an index of DA release (Westerink and Spaan, 1982; Wood et al., 1982; Westerink, 1985; Wood and Altar, 1988; Brown et al., 1991), while evidence has been presented to show that most of the DOPAC and HVA in the brain derives from a pool of DA that has never been released (Commissiong, 1985; Zetterstrom et al., 1988; Garrett and Soares-da-Silva, 1990; Soaresda-Silva and Garrett, 1990). Therefore, high levels of acid metabolites accompanied by either increased or decreased 3-MT levels may depend on intracellular metabolism in monoaminergic as well as in nonmonoaminergic elements (Garrett and Soares-da-Silva, 1990; Soares-da-Silva and Garrett, 1990). On the other hand, it has been shown that 3-MT levels in the NAS of stressed mice follow a time-dependent evolution similar to that observed for DA outflow in the NAS of stressed rats (Puglisi-Allegra et al., 1991), as measured by intracerebral microdialysis; and a large body of converging evidence supports the assumption that this last method provides an accurate index of released DA (Imperato and Di Chiara, 1984; Kuczenski and Segal, 1989). Taken together, these considerations support the view that exposure to controllable shock elicits an increase of mesolimbic DA release while exposure to uncontrollable shock induces a decrease of DA release in this brain area.

The different patterns of mesolimbic DA response observed in the three experimental conditions could depend on the different motor responses elicited by these conditions. It has been reported that mice exposed to inescapable shock show a progressive decrease of locomotion as measured in a circular activity meter (Anisman et al., 1978). However, there are no reports in the literature indicating that low levels of activity are accompanied by inhibition of DA release. By contrast, data from 

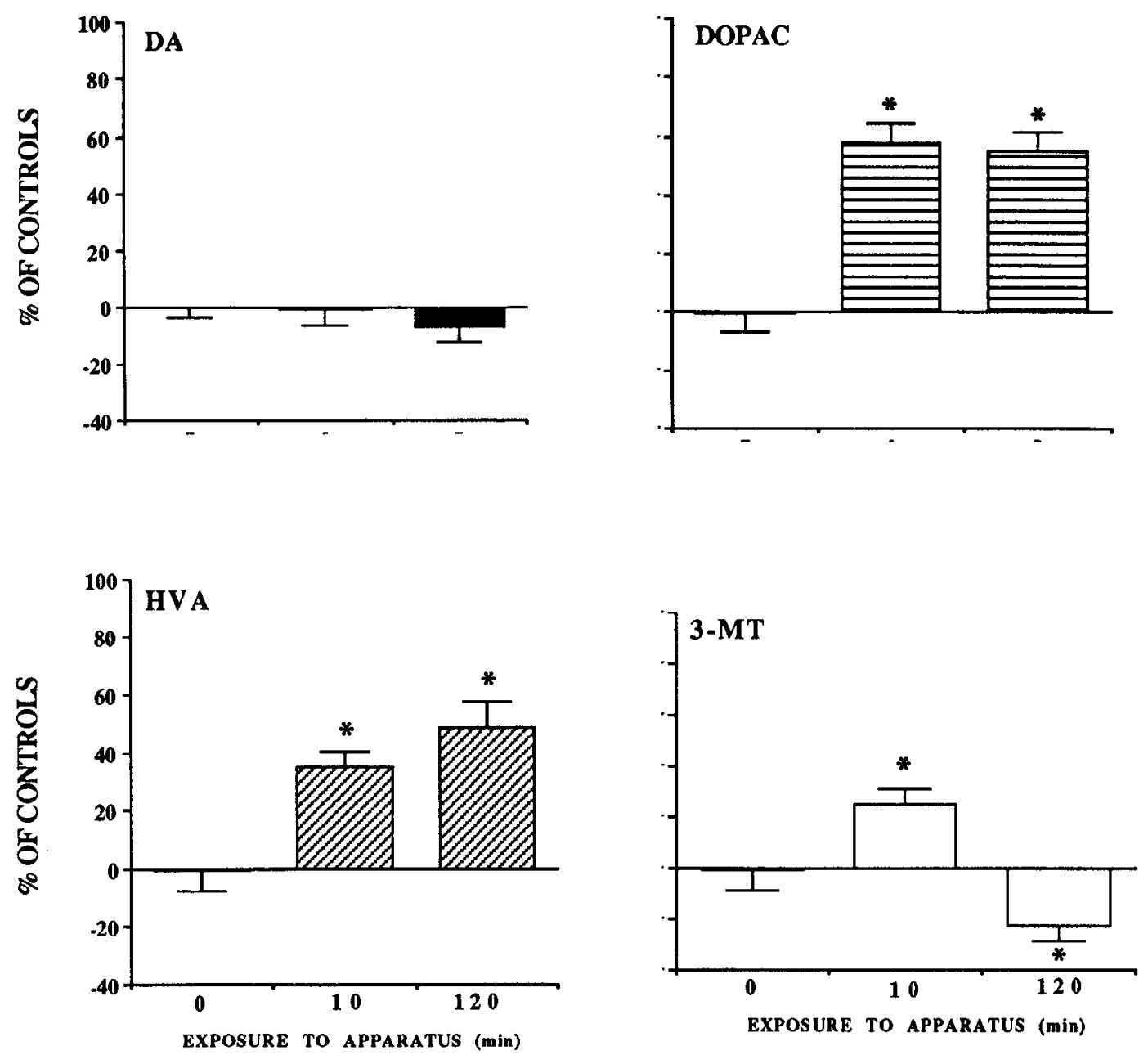

Figure 3. Effects of 10 or 120 min and no treatment (0) on DA and DA metabolites in the NAS of DBA/2 mice. Results are expressed as percentage changes $( \pm$ SEM) from control lcvels. Statistical analyses were performed on tissue levels (ng/gm wet weight). Levels in controls were as follows: $\mathrm{DA}=12,082 \pm 409 ; \mathrm{DOPAC}=1054 \pm 62 ; \mathrm{HVA}=1018 \pm 69 ; 3-\mathrm{MT}=70.4 \pm 3.4{ }^{*}, p<0.05$ in comparison with 0 (Duncan test).

dialysis experiments appear to rule out this possibility. In these experiments, baseline levels are obtained following $120 \mathrm{~min}$ of stabilization, when levels of DA and metabolites do not differ by more than $7 \%$ over three consecutive samples $(3 \times 10 \mathrm{~min})$ (Puglisi-Allegra et al., 1991). The duration of the process and the stability of DA outflow suggest that during baseline sampling, exploration of the experimental environment ceases and active behavior is very low or absent. Consequently, a progressive decrease in activity in stress conditions should produce a return of DA outflow to basal levels. Nonetheless, stressed animals show a significant decrease of DA outflow below baseline levels.

On the other hand, animals exposed to aversive stimuli can show a state of rigid immobility known as freezing and an increase in the number of freezing episodes could account for the decreased activity produced by inescapable shock and explain an inhibition of mesolimbic DA release. However, two independent laboratories using different approaches and species have shown that freezing is accompanied by enhanced mesolimbic DA release (Louilot et al., 1986; Puglisi-Allegra and Cabib, 1990). These data, together with data obtained in different experimental conditions (Meisel et al., 1993) also indicate that an increase of DA relcase is not always associated with high levels of locomotor activity. Finally, previously published data on sham, shocked, and yoked motor responses during the experimental session (Weiss et al., 1981) indicated the sham group as showing the lowest levels of activity $(-92 \%$ compared with yoked levels). However, in the present experiments, exposure to the sham condition produced only a nonsignificant decrease of 3-MT levels in the NAS while a significant decrease was observed in the yoked condition. Taken together, these results do not support a motor explanation for the differences in mesolimbic DA response observed in the present experiments.

It has previously been shown that exposure to unavoidable aversive conditions produces a time-dependent biphasic alteration of DA release in the NAS (Puglisi-Allegra et al., 1991). In particular, it was shown that in the NAS of DBA/ 2 mice exposed to unavoidable shock an increase of 3-MT levels was evident during the first 3-10 min of shock exposure followed by a return to basal levels at $30 \mathrm{~min}$ and by a subsequent reduction below control levels at $60 \mathrm{~min}$. The present results showing an increase of 3-MT levels in the NAS exposed to 60 min of escapable shock clearly indicate that the possibility of exerting behavioral control over an aversive situation disrupts the time-dependent evolution of mesolimbic DA response to stress.

The decrease of mesolimbic 3-MT induced by prolonged exposure to an aversive situation has been shown to be prevented by pretreatment with the opioid antagonist naltrexone (Cabib 
et al., 1989), suggesting that endogenous opioids play a major role in the control of the inhibitory phase of mesolimbic DA response to stress. Many lines of evidence indicate that endogenous opioids are released during uncontrollable but not during controllable stress (Amir et al., 1980; Maier et al., 1983). Consequently, it may be suggested that the absence of endogenous opioid release prevents inhibition of DA release in mice exposed to escapable shock.

Mice exposed to the apparatus without receiving shock (sham) for a period matching shocked and yoked groups $(60 \mathrm{~min})$ show increased DOPAC and HVA levels and a nonsignificant reduction of 3-MT levels in the NAS. Examination of time-dependent variations of DA metabolism in the NAS of mice exposed to this condition reveals the typical time-dependent evolution induced by exposure to an aversive situation (Puglisi-Allegra et al., 1991; Cabib et al., 1993). This is not surprising since a number of results indicate that confinement within an unknown environment represents a stressful experience for mice (Cabib et al., 1990; Prince and Anisman, 1990). Moreover, the reduction of 3-MT levels observed in mice exposed to the sham condition for $120 \mathrm{~min}$ is roughly similar to that observed in the yoked group. Consequently, the pattern of DA metabolites observed in the NAS of mice exposed for $60 \mathrm{~min}$ to the sham condition is due to the fact that at this point in time DA release is no longer activated and DA inhibition is just starting to take over. These results indicate that the intensity of the aversive condition modulates the temporal evolution of the inhibition of DA release induced by stress. On the other hand, the increase of mesolimbic DA release observed in mice exposed for $60 \mathrm{~min}$ to escapable shock but not in mice exposed to the apparatus for the same time without receiving shock suggests that only in those situations that allow behavioral coping is the initial response of the mesolimbic DA system to stress maintained, regardless of the intensity of the aversive stimuli.

The DA response in the FC does not follow the pattern observed in the NAS. Neither DOPAC nor HVA levels in the FC are affected by $60 \mathrm{~min}$ of exposure to the sham condition and a different increase of DOPAC levels is observed in shocked and yoked conditions (yoked $>$ shocked). Moreover, although not statistically significant, similar differences are observable for HVA levels. As previously discussed, the ex vivo levels of acid metabolites do not represent a good index of DA release, and data on time-dependent variations of DA outflow in the NAS and FC of restrained rats (Imperato et al., 1991) do not indicate different responses of the two DA systems. Nonetheless, it has been suggested that the mesocortical DA system may be more involved than the accumbens in cognitive processes (see Le Moal and Simon, 1991, for review). Consequently, it is also possible that the different changes in acid DA metabolites levels observed in the FC reflect the ability of this system to discriminate between differences in the intensity of the aversive stimuli in the three experimental conditions. Further investigations using different experimental and methodological approaches will possibly elucidate this point.

Finally, the present results suggest possible relationships between some of the behavioral alterations induced by unavoidable stress and mesolimbic DA response. In fact, the strain of mice used for these experiments is susceptible to some but not all the behavioral alterations induced by acute stress (Shanks and Anisman, 1988; Zacharko and Anisman, 1991).

Although one of the most thoroughly studied effects of unavoidable stress is the behavioral impairment also known as learned helplessness (Maier and Seligman, 1976; Anisman et al., 1978), DBA/2 mice are not susceptible to this behavioral effect of stress (Shanks and Anisman, 1988). Consequently, stressinduced inhibition of DA release in the NAS cannot account for this behavioral impairment, which possibly involves stress effects on a different mediator or on a different brain system (Anisman et al., 1979; Weiss et al., 1985; Maier et al., 1983).

On the other hand, DBA/ 2 mice are highly susceptible to stress-induced disruption of intracranial self-stimulation from the NAS (Zacharko and Anisman, 1991). This effect has been observed following uncontrollable but not controllable shock and appears to be dependent on the reduction of motivation or of the reinforcing propertics of an otherwise rewarding stimulus (Zacharko et al., 1983). Since DA has been shown to play a major role in the modulation of motivation and reward (Fibiger et al., 1987; Koob and Bloom, 1988; Robbins et al., 1989; Wise and Rompe, 1989), inhibition of DA release in the NAS induced by unavoidable stress might explain reduced responding for selfstimulation from this brain area. Moreover, several lines of evidence suggest that stress-induced reduction of intracranial self-stimulation may simulate the anhedonia of human depression (see Zacharko and Anisman, 1991, for review). Consequently, the present results suggest a neural mechanism through which stress may favor the development of depressive states.

In conclusion, the present results are in line with the hypothesis that in environmental conditions that allow behavioral coping, stress-induced inhibition of mesolimbic DA release is prevented. These results also indicate that intensity of the aversive stimuli modulates the temporal evolution of the inhibition of DA release induced by stress. Moreover, they suggest that exposure to different aversive experiences could elicit different responses in the FC DA system. Finally, a possible implication of stress-induced alterations of mesoaccumbens DA functioning in human depressive states may be envisaged.

\section{References}

Abercrombie ED, Keefe KA, DiFrischia DF, Zigmond MJ (1989) Differential effects of stress on in vivo dopamine release in striatum, nucleus accumbens and medial frontal cortex. J Neurochem 52:16551658.

Amir S, Brown $\angle W$, Amit $\angle$ (1980) The role of endorphines in stress: evidence and speculations. Neurosci Biobehav Rev 4:77-86.

Anisman H, deCatanzaro D, Remington $G$ (1978) Escape performance following exposure to inescapable shock: deficits in motor response maintenance. J Exp Psychol [Anim Behav] 4:197-218.

Anisman H, Remington G, Sklar LS (1979) Effects of inescapable shock on subsequent escape performance: catecholaminergic and cholinergic mediation of response initiation and maintenance. Psychopharmacology 61:107 -.124.

Blanc G, Herve D, Simon H, Lisoprawski A, Glowinski J, Tassin JP (1980) Response to stress of mesocortico-frontal dopaminergic neurons in rats after long-term isolation. Nature 284:265-267.

Brown EE, Damsma C, Cumming P, Fibiger HC (1991) Interstitial 3-methoxytyramine reflects striatal dopamine release: an in vivo microdialysis study. J Neurochem 57:701-707.

Cabib S, Puglisi-Allegra S (1991) Genotype-dependent effects of chronic stress on striatal and mesolimbic dopamine metabolism in response to apomorphine. Brain Res 542:91-96.

Cabib S, Puglisi-Allegra S, Oliverio A (1985) A genetic analysis of stereotypy in the mouse. Behav Neural Biol 44:239-248.

Cabib S, Kempf S, Schleef C, Oliverio A, Puglisi-Allegra S (1988) Effects of immobilization stress on dopamine and its metabolites in different brain areas of the mouse: role of genotype and stress duration. Brain Res 441:153-160.

Cabib S, Oliverio A, Puglisi-Allegra S (1989) Stress-induced decrease in 3-methoxytyramine in the nucleus accumbens of the mouse is prevented by naltrexone pretreatment. Life Sci 45:1031-1037. 
Cabib S, Algeri S, Perego C, Puglisi-Allegra S (1990) Behavioral and biochemical changes monitored in two inbred strains of mice during exploration of an unfamiliar environment. Physiol Behav 47:749753.

Cabib S, Puglisi-Allegra S, D'Amato FR (1993) Effects of postnatal stress on dopamine mesolimbic responses to aversive experiences in adult life. Brain Res 604:232-239.

Commissiong JW (1985) Monoamine metabolites: their relationship and lack of relationship to monoaminergic neuronal activity. Biochem Pharmacol 34:1127-1131.

Deutch AY, Tam S, Roth R (1985) Foot-shock and conditioned stress increase 3,4-dihydroxyphenylacetic acid (DOPAC) in the ventral tegmental arca but not in the substantia nigra. Brain Res 33:143-146.

Dunn AJ, File SE (1983) Cold restraint alters dopamine metabolism in frontal cortex, nucleus accumbens and neostriatum. Physiol Behav $31: 511-513$.

Fibiger HC, Jakubovic A, Le Piane FG, Philips AG (1987) The role of dopamine in intracranial self-stimulation of the ventral tegmental area. J Neurosci 7:3888-3896.

Garrett MC, Soares-da-Silva P (1990) Role of type A and B monoamine oxidase on the formation of 3,4-dihydroxyphenylacetic acid (DOPAC) in tissues from the brain of the rat. Neuropharmacology 29:875-879.

Gora-Maslak G, McClearn GE, Crabbe JC, Phillips TJ, Belknap JK, Plomin R (1991) Use of recombinant inbred strains to identify quantitative trait loci in psychopharmacology. Psychopharmacology 104:413-424.

Green KA, Beck O, Faull KF, Stavinoha WB (1988) Mouse brain concentrations of 3-methoxytyramine and normetanephrine: a comparison between methods of sacrifice. Neurochem Int 12:47-52.

Herman JP, Guillenau D, Dantzer R, Scatton B, Semerdjian-Roquier L, Le Moal M (1982) Differential effects of inescapable footshocks and of stimuli previously paired with inescapable footshocks on dopamine turnover in cortical and limbic areas of the rat. Life Sci 30: 2207-2214.

Imperato A, Di Chiara G (1984) Trans-striatal dialysis coupled to reverse phase high performance liquid chromatography with electrochemical detection: a new method for the study of in vivo release of endogenous dopamine and metabolites. J Neurosci 4:966-977.

Imperato A, Puglisi-Allegra S, Casolini P, Angelucci L (1991) Changes in dopamine and acetylcholine release during and following stress are independent of the pituitary-adrenocortical axis. Brain Res 538:111117.

Imperato A, Angelucci L, Casolini P, Zocchi A, Puglisi-Allegra S (1992) Repeated stressful experiences differently affect limbic dopamine release during and following stress. Brain Res 577:194-199.

Imperato A, Cabib S, Puglisi-Allegra S (1993) Repeated stressful experiences differently affect the time-dependent responses of the mesolimbic dopamine system to the stressor. Brain Res 601:333-336.

Koob GF, Bloom FE (1988) Cellular and molecular basis of drug dependence. Science 242:715-723.

Kuczenski R, Segal DS (1989) Concomitant characterization of behavioral and striatal neurotransmitter response to amphetamine using in vivo microdialysis. J Neurosci 9:2051-2065.

Laudenslager ML, Ryan SM, Drugan RC, Hyson LR, Maier SF (1983) Coping and immunosuppression: inescapable but not escapable shock suppress lymphocyte proliferation. Science 221:568-570.

Le Moal M, Simon H (1991) Mesocorticolimbic dopaminergic network: functional and regulatory role. Physiol Rev 71:155-234.

Levine S, Wiener SG (1989) Coping with uncertainty: a paradox. In: Coping with uncertainty: behavioral and developmental perspectives (Palermo DS, ed), pp 1-17. Hillsdale, NJ: Erlbaum.

Louilot A, Le Moal M, Simon H (1986) differential reactivity of dopaminergic neurons in the nucleus accumbens in response to different behavioral situations. An in vivo voltametric study in freely moving rats. Brain Res 397:395-400.

MacLennan AJ, Maier SF (1983) Coping and stress-induced potentiation of stimulant stereotypy in the rat. Science 219:1091-1093.

Maier SF, Seligman MEP (1976) Learned helplessness: theory and evidence. J Exp Psychol [Gen] 105:3-46.

Maier SF, Sherman JE, Lewis JW, Terman GW, Liebeskind JC (1983) The opioid/nonopioid nature of stress-induced analgesia and learned helplessness. Anim Behav Proc 9:80-90.

Meisel RL, Camp DM, Robinson TE (1993) A microdialysis study of ventral striatal dopamine during sexual behavior in female Syrian hamsters. Behav Brain Res 55:151-157.

Oliverio A, Cabib S, Puglisi-Allegra S (1992) Nonhuman behavioral models in the genetics of disturbed behavior. J Psychiatr Res $367-$ 382.

Plomin R (1990) The role of inheritance in behavior. Science 183: 183-188.

Prince CR, Anisman H (1990) Situation-specific effects of stressor controllability on plasma corticosterone changes in mice. Pharmacol Biochem Behav 37:613-621.

Puglisi-Allegra S, Cabib S (1990) Effects of defeat experiences on dopamine metabolism in different brain areas of the mouse. Aggressive Bchav 16:271-283.

Puglisi-Allegra S, Imperato A, Angelucci L, Cabib S (1991) Acute stress induces time-dependent responses in dopamine mesolimbic system. Brain Res 554:217-222.

Robbins TW, Cador M, Taylor JR, Everitt BJ (1989) Limbic-striatal interactions in reward-related processes. Neurosci Biobehav Rev 13 155-162.

Shanks N, Anisman H (1988) Stressor provoked behavioral changes in six strains of mice. Behav Neurosci 102:894-905.

Shanks N, Griffits J, Zalcman S, Zacharko RM, Anisman H (1990) Mouse strain differences in plasma corticosterone following uncontrollable footshock. Pharmacol Biochem Behav 36:515-519.

Shanks N, Zalcman S, Zacharko RM, Anisman H (1991) Alterations of central norepinephrine, dopamine and serotonin in several strains of mice following acute stressor exposure. Pharmacol Biochem Behav 38:69-75.

Sidman RL, Angevine JB, Pierce ET (1970) Atlas of the mouse brain and spinal cord. Cambridge, MA: Harvard UP.

Simon H, Le Moal M (1984) Mesencephalic dopaminergic neurons: functional role. In: Catecholamines, Pt B, Neuropharmacology and central nervous system - theoretical aspects (Usdin E, Carlsson A, Engel J, eds), pp 297-307. New York: Liss.

Soares-da-Silva P, Garrett MC (1990) A kinetic study of the rate of formation of dopamine, 3,4-dihydroxyphenylacetic acid (DOPAC) and homovanillic acid (HVA) in the rat brain: implications for the origin of DOPAC. Neuropharmacology 29:869-874.

Stevens JR (1979) Schizophrenia and regulation of the mesolimbic system. Trends Neurosci 2:102-105.

Swerdlow NR, Koob GF (1987) Dopaminc, schizophrenia, mania and depression: toward a unified hypothesis of cortico-striato-pallido-thalamic function. Behav Brain Sci 10:197-245.

Vulto GA, Westenberg HGM, Meijer LBA, Versteeg DHG (1986) The dopamine metabolite 3-methoxytyramine is not a suitable indicator of dopamine release in the rat brain. J Neurochem 47:1387-1393.

Weiss JM, Goodman-Simson PA (1985) Neurochemical mechanisms underlying stress-induced depression. In: Stress and coping, Vol 1 (Field T, McCabe P, Scheiderman N, eds), pp 93-1 16. Hillsdale, NI: Erlbaum.

Weiss JM, Goodman PA, Losito BG, Corrigan S, Charry JM, Bailey WH (1981) Behavioral depression produced by an uncontrollable stressor: relationship to norepinephrine, dopamine, and serotonin levels in various regions of rat brain. Brain Res Rev 3:167-205.

Westerink BHC (1985) Sequence and significance of dopamine metabolism in the rat brain. Neurochem Int 7:221-227.

Westerink BHC, Spaan SJ (1982) On the significance of endogenous 3 -methoxytyramine for the effects of centrally acting drugs on dopamine release in the rat brain. J Neurochem 38:680-686.

Willner P (1983) Dopamine and depression: a review of recent evidence. Brain Res Rev 6:211-246.

Wise RA, Rompe PP (1989) Brain dopamine and reward. Annu Rev Psychol 40:191-225.

Wood PL, Altar A (1988) Dopamine release in vivo from nigrostriatal, mesolimbic, and mesocortical neurons: utility of 3-methoxytyramine measurements. Pharmacol Rev 40:163-187.

Wood PL, Nair NPV, Bozarth M (1982) Striatal 3-methoxytyramine as an index of dopamine release: effects of electrical stimulation. Neurosci Lett 32:291-294.

Wood PL, Altar CA, Kim HS (1988) Presynaptic inhibition of nigrostriatal dopamine release in the mousc: lack of cross tolerance between apomorphine, GBL and CGS 10746B. Life Sci 42:15031506.

Zacharko RM, Anisman H (1991) Stressor-induced anhedonia in the mesocorticolimbic system. Neurosci Biobehav Rev 15:391-405. 
Zacharko RM, Bowers WJ, Kokkinidis L, Anisman H (1983) Regionspecific reductions of intracranial self-stimulation after uncontrollable stress: possible effects on reward processes. Behav Brain Res 9:129141.

Zacharko RM, Lalonde G, Kasian M, Anisman H (1987) Strain-specific effects of inescapable shock on intracranial self-stimulation from the nucleus accumbens. Brain Res 426:164-168.
Zetterstrom T, Sharp T, Collin AK, Ungerstedt U (1988) In vivo measurement of extracellular dopamine and DOPAC in rat striatum after various dopamine-releasing drugs: implications for the origin of the extracellular DOPAC. Eur J Pharmacol 148:327-334. 